\title{
Determinants of RFID Adoption in Supply Chain among Manufacturing Companies in China: A Discriminant Analysis
}

Liu Wen, Suhaiza Zailani, Yudi Fernando *

\begin{abstract}
The growth of China's economy hinges to a large extent on the ability of the industry to operate more efficiently and effectively in the global supply chain system. China's manufacturing companies should pay attention to adopt more efficient supply chain technologies to provide better services for their customers. China has initially carried out research and development and industrialization of technology related to RFID and begun to apply in some areas in recent years. This article studies the determinant factors of the RFID adoption by manufacturing companies in China. The population of this study is manufacturing companies in China that are registered under Federation of China Manufacturers. A questionnaire survey is conducted to study the adoption of RFID by China's manufacturing industry. This study reveals that the environment, organization, technology and product have the impact on the adoption of RFID in China. Organization should be given strategic attention to improve employee participation in adopting RFID as a strategic tool..
\end{abstract}

Keywords: Technology, RFID Adoption, Supply Chain, China.

* School Of Management, Universiti Sains Malaysia. I 1800 Penang, Malaysia.

Tel: (604) 6577888 ext 3952. Fax: (604) 6577448.E-mail:shmz@usm.my 


\section{Introduction}

In order to satisfy the diversifying requirements of customers, many manufacturing companies improve their service efficiency by continuous adoption of information or automation technologies (Mason-Jones \& Towill, 1999; Sauvage, 2003). Many studies have found that innovation is the most important tool for enterprises to keep their competitive advantage (Kimberly \& Evanisko, 198I; Damanpour \& Evan, 1984). The survival of an enterprise in the age of knowledge-based economy depends on how to improve their organizational innovation capability. Technological innovation is the key variable and the means of differentiation between companies (Sauvage, 2003). Nixon (200I) suggests that manufacturing companies should employ new information technologies to raise their service capability in the e-commerce age. Speakman (2002) proposes that companies could increase their performance by employing new technologies. Chapman, Soosay and Kandampully (2003) suggest that the industry should pay more attention to innovation in supply chain, and the innovation in supply chain can be implemented through technology, knowledge and relationship networks. Adopting new technologies might enable companies in China to enhance their service abilities.

More than two decades of economic reform and transition to market economy has brought China unprecedented economic growth. With the fast growth in China's economy and China's accession to World Trade Organization (WTO), the demand for manufacturing companies has been growing significantly in China, and the manufacturing industry in China is set to take off. A study by Fusion Consulting (2004) has revealed that Radio Frequency Identification (RFID) technology has had a huge impact on the manufacturing sector particularly in the area of distribution and retail globally. The RFID technology is a type of non-con-contact automatic identification technology, which can substantially improve the management and operation efficiency when used in industries of logistics, manufacture and public information service. The development of RFID technology and application, which is a sophisticated systematic work, influences many areas such as economy and society, and involves many industries and government authorities. It also needs overall planning, research and development, and coordinates enterprises and governments for the sake of complementary advantages to the maximum extent. RFID has shown great capabilities in uniquely identifying objects, and potentials towards many industries such as supply chain management, telemetry and patient movement detection (Yu, 2007).

In conjunction with this, for 2005 , some experts have predicted rapid growth of RFID in China, while others contend that the RFID market is still in its infancy and will have limited growth (China Economic Times, 2004). All RFID projects in China are relatively small and are still in a pilot test stage, especially when compared to developed countries, like the USA, where the RFID industry chain includes mature and large-scale projects from giant businesses, such as Wal-Mart and DHL (Lai et al., 2005). In a survey of a hundred executives from major manufacturing and retailing companies from Asia-Pacific countries, Accenture (2004) found out that Chinese executives predicted high returns on their RFID investments. Of these executives, 18 percent anticipated implement RFID beginning in 2006, while 45 percent indicated that they would implement RFID in 2007 or later.They indicated that the greatest barriers to RFID adoption in China were the costs of overall implementation, the costs of tags, and the lack of standards (Lai et al., 2005). The Chinese Ministry of Science and Technology (MOST), a primary RFID decision-making government body, has identified several preliminary application areas to focus its efforts and resources for RFID, including:

- Public safety and security: Medical and health, food safety, hazardous articles management, anti-forgery security, coalmine safety, electronic license, animal identification (involving public hygiene and safety) and door access management;

- Production management and control: Specific areas include automobile manufacturing, home appliance production, and textile and apparel manufacturing;

- Modern logistics and supply chain management: Specific application areas include warehousing management, logistics distribution, retail management, container transportation and postal service;

- Traffic management: Specific application areas include public transport tickets, non-stop billing, vehicle management and management of railway locomotives, vehicles and relevant facilities;

- Military logistics:Specific application areas include the military materials and equipment management, precise and accurate identification of transport units and fast positioning and active searching; and

- Major public activities and events: Large-scale sports meetings and exhibitions, specifically including ticket management, vehicle management and facility

However, Fusion (2007) surveyed I 36 international and local manufacturers located in Guangdong and Hong Kong and found that 94 percent of which indicated that they are currently not interested in adopting RFID technology for tracking their merchandise. He added that of the 93 companies that had clear reasons for not adopting RFID, the main obstacle is ignorance: 
44 percent said that they either did not "understand and/or were not familiar" with RFID. However, according to Wong of China Elite Technology and a member of the advisory board to EPC global Hong Kong (2006), the adoption of RFID remains unsatisfactory not only in South China-based companies but also in companies through out the Middle Kingdom. One reason, he says, is that Chinese companies have not found a good reason to invest in the technology. That's because unlike in America, where RFID tagging has helped in reducing labor costs by automating the process of tracking goods, labor in China is cheap and widespread. Wong added that many Chinese manufacturers don't have a sophisticated IT environment in place, which makes setting up an RFID system more complicated than simply buying interrogators (readers) and tags.

It is clearly seen that RFID adoption in the manufacturing industry in China is still low. There are not a lot of companies in China that really do know how to implement RFID correctly, and many of them are still lack of the awareness of what RFID can or cannot do. Marcus (2005) said the company is lacking an understanding of what factors influence companies' decision whether or not to start using RFID and is also interested in learning what potential customers need from an RFID solution. The objective of this paper is, therefore, to investigate the determinants of RFID adoption in China through discriminant analysis. The next section presents a summary of RFID and follows by the theoretical foundations of the determinants of RFID. Section four gives a description of the research methodology, while section five focuses on the analysis of the results and the discussion of the findings. The final section gives conclusions and research's implications.

\section{Literature Review}

\section{I E-Business and a Company's' Value Chain}

Michael Porter is widely credited with popularizing the term "value chain" in his 1985 book, "Competitive Advantage". Value Chain Analysis is based on the simple idea that every activity performed within an organization adds some value to the final goods or service produced by that particular organization. Porter's framework of the company value chain and value system between companies remains useful to understand the relevance of e-business in this context. A value chain logically presents the main functional areas ('value activities') of a company and differentiates between primary and support activities. However, these are "not a collection of independent activities but a system of interdependent activities", which are "related by linkages within the value chain".These linkages can lead to competitive advantage through optimization and coordination. This is where ICT can have a major impact, in the key role of optimizing linkages and increasing the efficiency of processes chan- nel (Johnston \& Lawrence, 1988). The value system expands this concept by extending its scale beyond the single company. The firm's value chain is linked to the value chains of (upstream) suppliers and (downstream) buyers; the resulting larger set of processes is referred to as the value system. All e-commerce and therefore electronic transactions occur within this value system.

\subsection{Radio Frequency Identification (RFID)}

Emerging as one of the most pervasive technologies ever developed, RFID is gaining popularity as a technology of automatic identification (Roberts, 2006). By allowing organizations to track their physical assets and maintain information about items at all times, RFID allows for complete information integration within the supply chain (Nikam \& Satpute, 2004). In this sense RFID meets the competitive organization's need to 'sense and respond' through integration of IT infrastructure (Nikam \& Satpute, 2004). RFID works by allowing a reader to read and write to a remote transponder (also called a tag) through electromagnetic waves (Curtin et al., 2005). In this sense, RFID improves on barcode scanning by allowing for the identification of items without line-of-sight being necessary between the reader and the tag (Curtin et al., 2005).

Companies use RFID mainly for three purposes: to reduce cost, to better serve customers, and to support business growth through for example increasing market share (Hassan, 2008). In essence, the majority of RFID projects in organizations explicitly or implicitly address one or several of these objectives. According to Roberts (2006), in almost every case, RFID introduction can be regarded as an ICT-enabled process innovation. Understanding one's business processes, and having a clear vision how they could be improved (be it to save costs or to improve service quality), are therefore critical requirements for firms to effectively use RFID. The increasing competitive pressure on companies, many of them operating in a global economy, has been a strong driver for ICT adoption in general and RFID in particular.

As the adoption of RFID technology is moving from mandatory to voluntary, firms are looking for tools, frameworks and methodologies to enable them to evaluate the real impact of RFID technology on their business processes (Linda \& Samuel, 2007). Nonetheless, the biggest potential lies in RFID can be used for item tracking, especially useful for global supply chain. Once all goods are attached with RFID tags, their whereabouts can be tracked automatically by radio readers, which give complete inventory visibility and supply chain management efficiency (Wu et al., 2006). The global industry for RFID technology has been growing steadily since past few years and is expected to grow rapidly before stabilizing and settling on a 
steady growth path. Sharma (2007) analyze the literature of adoption and diffusion of innovation and extract a number of factors which are grouped to organizational readiness factors, technology factors, external environment factors and inter-organizational pressure factors.

The factors are then used as key words and respectively variables in semi-structured interviews with industry experts and numerous news reports and tested for significance to RFID technology adoption and diffusion. The most mentioned factors are the perceived benefit of the technology, costs the existence of a dominant supply chain partner, intellectual property and ownership standards adoption, data and software standards, diffusion champion presence, and top management support. In addition, RFID adoption is moderating via supply chain. Today, retailers and manufacturers are using RFID technologies to manage the supply chains (Huber et al., 2007). In a sense, pervasive standards across the supply chain are necessary to encourage adoption, while adoption is stunted by the lack of standards (Asif \& Mandviwalla, 2005), and so most supply chain organizations are reluctant to adopt.

\subsection{Determinants of RFID}

The global industry for RFID technology has been growing steadily since past few years and is expected to grow rapidly before stabilizing and settling on a steady growth path. Sharma (2007) analyze the literature of adoption and diffusion of innovation and extract a number of factors which are grouped to organizational readiness factors, technology factors, external environment factors and inter-organizational pressure factors. Since the adoption of RFID technology is also could be considered as adoption of innovation, there is a large body of research done on the determinants of innovation (Kimberly and Evanisko, 1981; Amabile, 1988; Tornatzky and Fleischer, 1990; Damanpour, 1991; Wolfe, 1994; Tidd et al, 1997). Kimberly and Evanisko (I98I) suggest that the individual factor, organizational factor and contextual factor would influence the adoption by hospitals of technological innovation. Variables affecting technology adoption are classified into individual, task-related, innovation-related, organizational and environmental characteristics. Tornatzky and Fleischer (1990) suggest that the adoption and implementation of technological innovation would be affected by the technological context, organizational context and the external environmental context. Patterson, Grimm and Corsi (2003) indicate that technology adoption is affected by organizational size, structure and performance, supply chain strategy, transaction climate, supply chain member pressure and environmental uncertainty. Scupola (2003) use technological, organizational and environmental characteristics to explain the adoption of Internet commerce. This article will investigate the influence of technological, organizational, environmental factors and product on the adoption of RFID by China's companies.

\subsection{Environment}

In much the same way that an innovative organizational culture encourages adoption of new technologies, thus, whether they are from within or outside of the organization, demands will always help to encourage adoption. This is because a technology can add to value by reducing costs or enhancing quality (Asif \& Mandviwalla, 2005), and so environmental conditions can have the impact on adoption. However, 'innovation attributes' make RFID a suitable technology to meet the demands of the supply chain; real advantage can only be gained in the supply chain when suppliers and customers are collaborating. This implies that willingness of both parties to improve their business processes might facilitate the adoption of a technology that will bring benefits to both of them (Fawcett et al., 2006). It can therefore be hypothesized as

$\mathrm{HI}$ : An organization chooses to adopt RFID or not is influenced by environment factors.

\subsubsection{Organization}

Organizations are increasingly required to incorporate new technology into business practices to improve competitiveness (Shan et al., 2008). Thus, organization-wide readiness is also an important factor for adoption of RFID (Asif \& Mandviwalla, 2005).An organization that is logistically innovative in its use of technology, using, for instance, EDI to streamline its document processing, is usually more willing to adopt RFID (Asif \& Mandviwalla, 2005), as it is within its nature and organizational culture to do so. Following by this idea, Patterson et al. (2003), consider organization size to be a significant consideration in organizational technology adoption. They have found that larger organizations generally have extra capacity to devote to finding new technologies and generating economies of scale from them. Grover and Goslar (1993) hold the theory that larger organizations are generally more willing to adopt new technologies, because they have the financial resources to back the change. It can therefore be hypothesized as

$\mathrm{H} 2$ :An organization chooses to adopt RFID or not is influenced by organizational factors.

\subsubsection{Technology}

Although there are compelling reasons to adopt RFID to replace barcodes, a few core issues exist: technology, standards, cost and privacy (Vic, 2006). Technological implementations rarely go exactly as planned since new technology brings new challenges. RFID systems are still developing common standards 
and protocols for use in the supply chain (Vic, 2006). While costs for readers and tags are becoming more affordable, the software development, integration and implementations, and supporting infrastructure costs are very high. The risk of being outdated due to rapidly evolving standards makes the adoption less attractive. In Schmitt et al. (2006) argues the current trend does not necessarily allow for extrapolations of future developments since technology adoption can hardly be regarded as a linear process. It can therefore be hypothesized as

H3: An organization chooses to adopt RFID or not is influenced by technology factors.

\subsubsection{Product}

RFID has made significant strides in the past three years. We are still in the early stages of extracting its maximum benefits. The advanced data capture capabilities of RFID technology coupled with unique product identification and real-time digital information coming from different data sources, such as environ- mental sensors, define a new and rich information environment that opens up new horizons for efficient decision-making activities (George, 2007). For suppliers to benefit from RFID, they need to share RFID information with their partners and exploit this information in order to streamline enterprise collaboration and gain new market knowledge (Subramani, 2004). From the review, it is noted that although many factors related to TQM adoption have been widely examined, RFID adoption, in consideration of top management commit, internal assessment, employee participation, have not been taken considerable attention from the researchers. It can therefore be hypothesized as

H4: An organization chooses to adopt RFID or not is influenced by product factors.

\subsection{Methodology}

The theoretical framework is served to investigate the influential factors (independent variables) that may contribute to the RFID adoption (dependent variable (refer Figure I).

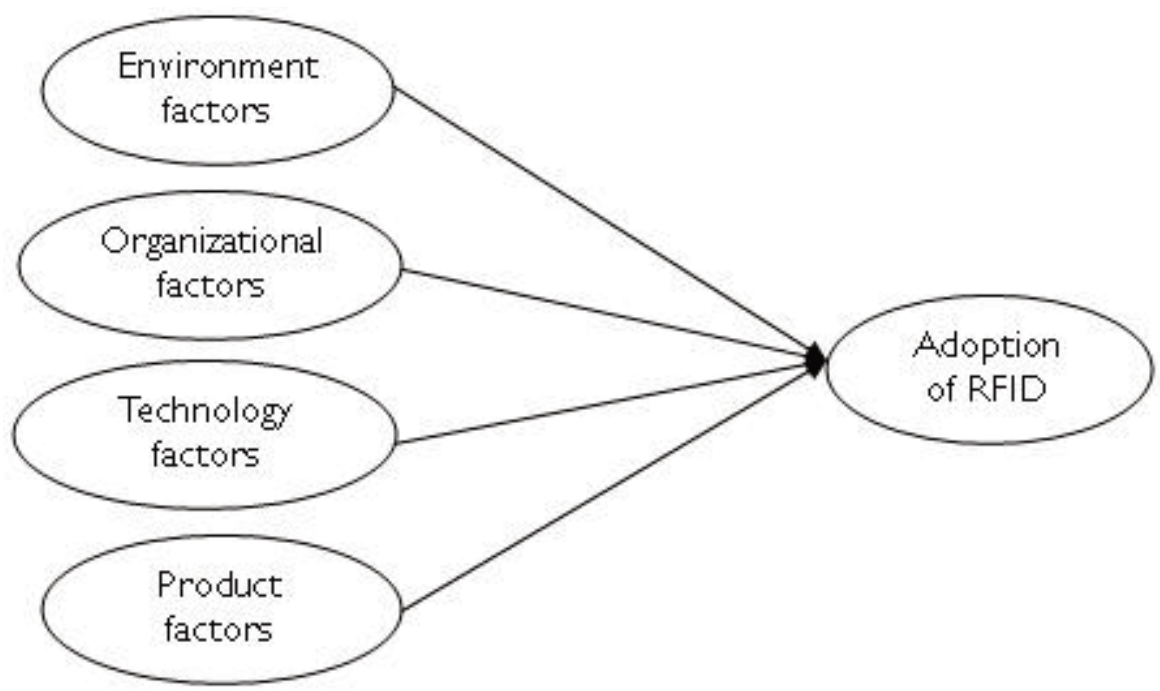

Figure I - The Framework of Adoption of RFID in China

\section{I Sample}

The population of this study comprises of all the manufacturing companies in China that are registered under Federation of China Manufacturers. Sekaran (2003) suggested that the analysis samples should be at least 10 times the number of variables in a study. Thus, 50 respondents are targeted in this study, as there are a total of 5 variables. Data collection was conducted based on personally administered questionnaire. The respondents for this study were targeted to be the people as they would have the knowledge and influence towards the RFID adoption. In order to obtain sufficient samples for analysis, 200 sets of the questionnaires were distributed to representatives who worked in agriculture, manufacturing, logistics/supply chains, banking, chemical, civil/construction, electrical and electronic, industrial and engineering, IT/ computer, sales, trading and so on industry that could personally reached their managers.

\subsection{Measurements}

Questionnaire was developed in consideration of the examples from previous literatures. For example, Environment (Question I-4) was measured by customers' pressure and competitive edge.These five-point scale measurements for customer's pressure were adopted from the study by Premkumar and Roberts (1999). Five-point scale measurements for the competitive edge 
were adopted from the study by Banerjee and Golhar (1994). Organizational (Question 5-8) were measured by the employee's information system knowledge and company support. Top management support was measured by two items in terms of sufficient funding and resources for RFID development and effective management control for RFID development. Five-point scale measurements for the organization characteristics were adopted from the study by Premkumar and Roberts (1999). Besides, employee's RFID knowledge was measured by two items in terms of employees have an understanding of RFID system based applications. Five-point scale measurements for the employee's information system were adopted from the study by Cragg and King (1993).

Technology (Question 9-I I) was measured by three items scale that evaluates the innovation at the administration department in the company in terms of new innovation in products/service by competitors, employees' innovation in information system, and up to date information system in administration department. Five-point scale measurements for the technological characteristics adopted from the study by lgbaria et.al. (1995). Product (Question 12-14) was measured by the three items scale that evaluate the relative advantage in terms of the recommendation for the company to use RIFD, bringing the good profit for the company, and allocating time, budget for information system innovation. Five-point scale measurements for the product characteristics adopted from the study by Igbaria et.al. (1995). RFID adoption is measured by differentiating the RFID adopter and non-adopter by asking whether the organization has even adopted RFID technique for management improvement.

\subsection{Discriminant Analysis}

Discriminant analysis was used to determine whether statistically significant differences exist between the average score profile on a set of variables for two a priori defined groups and so enabled them to be classified. Besides, it could help to determine which of the independent variables account the most for the differences in the average score profiles of the two groups (Hair et al. 1998). In this study, discriminant analysis was the main instrument to classify the RFID adopter and nonadopter. It was also utilized to determine which of the independent variables would contribute to RFID adoption.

\section{Results}

The sample data was obtained from I 30 companies from China, which constituted $65 \%$ response rate as 200 questionnaires were distributed.Among the respondents' organization, there was $54.6 \%$ owned by China, $23.8 \%$ was jointly and remaining of $21.5 \%$ non-China owned venture. This ratio is justifiable as most of the companies are located in Beijing.Among the respondents, $49.2 \%$ of the companies have adopted RFID technique while $50.8 \%$ revealed that there was no RFID activity in their companies. Based on data collected, majority of the foreign companies are involved in the IT and manufacturing section. About $29.2 \%$ (38) of companies have operated between 5 to 10 years, while approximately $15.4 \%$ (20) have experience between 10 to 15 years and $25.4 \%$ (33) have established 15 to 20 years. Meanwhile, $24.6 \%$ (32) of companies have established less than 5 years, whereas only about 5 percent of companies have established over than 20 years.

\section{I RFID Adopters Profile}

From Table I, it was obvious that most of the companies are new adopters whereby $4.6 \%$ of them implemented RFID techniques for not more than I year with $6.2 \%$ of them completed not more than I project.

\begin{tabular}{|l|l|l|l|}
\hline Variables & Description & Frequency & $\%$ \\
\hline Undergone any & No & 66 & 50.8 \\
RFID project & Yes & 64 & 49.2 \\
\hline & Less than Iyr & 6 & 4.6 \\
Yeas of using & Iyr to 2yrs & 25 & 19.2 \\
RFID experience & 3yrs to 4yrs & 18 & 13.8 \\
& 5yrs to 6yrs & 10 & 7.7 \\
& Above 6yrs & 8 & 6.2 \\
\hline \multirow{3}{*}{ The number of } & Less than I & 8 & 6.2 \\
the completed & 2 to 3 & 18 & 13.8 \\
RFID projects & 4 to 5 & 20 & 15.4 \\
& Above 5 & 11 & 8.5 \\
\hline
\end{tabular}

Table I - RFID Adopters Profile 


\subsection{Reasons for RFID no-adopters}

The main reasons that most of the companies which do not adopt RFID were lack of awareness on the concept, which is 19.2 percent showing in Table 2. The following reason is not prepared for RFID (I4.6\%). Lack of government assistance, resistance by suppliers, and resistance by employees were not considered for the reason for not adopting RFID which showed 51.5 percent in missing. Some other reasons for not adopting RFID, such as RFID does not related my work, also took .8 percent.

\begin{tabular}{|l|l|l|l|}
\hline Variables & Description & Frequency & $\%$ \\
\hline The Reason for & Lack of awareness on the concept & 25 & 19.2 \\
not Adopting & Lack of time & 6 & 4.6 \\
RFID & Budget constraint & 6 & 4.6 \\
& Not prepared for RFID & 6 & 14.6 \\
& Benefits less than cost & 1 & 4.6 \\
& Others & 67 & .8 \\
& Missing & 51.5 \\
\hline
\end{tabular}

Table 2 - The Reason for not Adopting RFID

\subsection{Reliability Analysis}

The items that represent each individual factor were subjected to reliability analysis. Determination of Cronbach's alpha coefficient of internal consistency is to ensure that the items comprising factors produced a reliable scale. A higher score will indicate a higher reliability, with a range from 0 to I. The ge- nerally agreed upon lower limit of Cronbach's alpha is 0.7 as mentioned by Nunnally and Bernstein (1994) with the lowest registering a value of .7168 (environment) and the highest .9584 (organizational). The rest of the variables technology (0.8444) and product $(0.928 \mathrm{I})$ have satisfactory alpha value. Table 3 shows that all factors are well kept above 0.7 .

\begin{tabular}{|l|l|l|l|}
\hline Factors & Label of variable & No. of items & Cronbach's alpha \\
\hline 1 & environment characteristics & 4 & .7168 \\
\hline 2 & organizational characteristics & 4 & .9584 \\
\hline 3 & technology characteristics & 3 & .8444 \\
\hline 4 & product characteristics & 3 & .9281 \\
\hline
\end{tabular}

Table 3 - Reliability of Independent Variables

\subsection{Descriptive Analysis}

In order to find out the determinant factors for RFID adoption, four independent variables, which were generated from the factor analysis, were used to classify the 130 respondents into RFID adopter and non-adopter by conducting the descriptive analysis. In this analysis, covariance matrix method was used to compute the descriptive function so that all of the in- dependent variables could be included in the analysis. The mean was applied as a measure of central tendency, which indicated that all variables were above their midpoint level as indicated in Table 4. Out of the four independent dimensions, environment was the highest in rating $(M=3.6192)$, followed by technology (3.582I), product $(3.4513)$ and organizational characters (3.1442).

\begin{tabular}{|l|c|c|}
\hline & Mean & Std. Deviation \\
\hline Environment & 3.62 & .58 \\
\hline Organizational & 3.14 & 1.05 \\
\hline Technology & 3.58 & .81 \\
\hline Product & 3.45 & .89 \\
\hline
\end{tabular}

Table 4 - Descriptive of Aggregated Variables 


\subsection{Discriminant and Predictive Validity}

Based on Wilk's Lambda and Univariate ANOVA to assess the significance between the means of the independent variables for the two groups, all variables showed significant univariate differences between the two groups at 0.05 level. According to Hair et al. (1998), discriminant loadings were considered relatively more valid than weights as a means of interpreting the discriminating power of independent variables because of their correlational nature, and any variables exhibiting a loading of \pm 0.30 or higher were considered substantive. Ranking of these variables in terms of their discriminating power were conducted by checking the value of the discriminant loadings and the univariate $F$ ratio. From Table 5 , we could see that both methods were corresponded to each other for all variables studied. From the below table, it is observed that the discriminant loadings of the four significant RFID adoption factors carry positive values. This indicated that the RFID adopters have paid more attention than the non-adopters on all the variables. In conclusion, the discriminant analysis has supported hypotheses, $\mathrm{HI}, \mathrm{H} 2, \mathrm{H} 3$ and $\mathrm{H} 4$. Summary of the hypotheses is showed in Table 6.

\begin{tabular}{|l|c|c|c|c|}
\hline $\begin{array}{l}\text { Independent } \\
\text { variables }\end{array}$ & $\begin{array}{c}\text { Discriminant } \\
\text { loading }\end{array}$ & Rank & $\begin{array}{c}\text { Univariate F } \\
\text { ratio }\end{array}$ & Rank \\
\hline Organizational & 0.575 & 1 & $94.659^{* *}$ & 1 \\
Product & 0.736 & 2 & $45.832^{* *}$ & 2 \\
Technology & 0.807 & 3 & $30.560^{* *}$ & 3 \\
Environment & 0.824 & 4 & $27.896^{* *}$ & 4 \\
\hline
\end{tabular}

** Significant at 0.0 i level, * Significant at 0.05 kevel

Table 5 - Summary of interpretive measures for discriminant analysis

\begin{tabular}{|c|c|c|}
\hline No & Hypothesis & Results \\
\hline $\mathrm{HI}$ & $\begin{array}{l}\text { An organization chooses to adopt RFID or not is influenced } \\
\text { by environment characteristics. }\end{array}$ & Accepted \\
\hline $\mathrm{H} 2$ & $\begin{array}{l}\text { An organization chooses to adopt RFID or not is influenced } \\
\text { by organizational characteristics. }\end{array}$ & Accepted \\
\hline $\mathrm{H} 3$ & $\begin{array}{l}\text { An organization chooses to adopt RFID or not is influenced } \\
\text { by technology characteristics. }\end{array}$ & Accepted \\
\hline $\mathrm{H} 4$ & $\begin{array}{l}\text { An organization chooses to adopt RFID or not is influenced } \\
\text { by product characteristics. }\end{array}$ & Accepted \\
\hline
\end{tabular}

\subsection{Validation of the results}

Table 6 - Summary of the Hypotheses Results

Classification accuracy of the model for the analysis sample, or

known as hit ratio was shown in Table 7.Accuracy of the analysis sample was 86.2 percent.

\begin{tabular}{|l|c|r|r|c|}
\hline & \multirow{2}{*}{ Adoption } & \multicolumn{2}{|c|}{ Predicted Group } & \multirow{2}{*}{ Total } \\
\cline { 3 - 4 } & & yes & \multicolumn{1}{c|}{ no } & \\
\hline Original Count & yes & 57 & 9 & 66 \\
\multirow{3}{*}{ Percent } & no & 9 & 55 & 64 \\
& yes & 86.4 & 13.6 & 100.0 \\
& no & 14.1 & 85.9 & 100.0 \\
\hline
\end{tabular}

Table 7 - Classification matrix for analysis sample 
To confirm the validity of the discriminant function, hit ratio of both analysis samples and holdout samples were compared to the respective percentage of being correctly classified by chance. The classification accuracy should be at least $25 \%$ greater than that achieved by chance (Hair et al. 1998). Apart from that, another measure of predictive accuracy of the model was using Press's Q. It compared the number of correct classification against the total samples and number of groups. Summary of the classification accuracy relative to chance was presented in the following table. The results showed that the discriminant function could predict better than chance.

\begin{tabular}{|l|c|c|}
\hline Measures & Analysis Samples & Holdout Samples \\
\hline Hit Ratio & $70.21 \%$ & $71.43 \%$ \\
Maximum Chance Criterion' & $53.19 \%$ & $52.38 \%$ \\
Proportional Chance Criterion ${ }^{2}$ & $50.20 \%$ & $50.11 \%$ \\
$25 \%$ greater than Chance value & $66.49 \%$ & $65.48 \%$ \\
\hline Press'5 Q value & 7.68 & 3.86 \\
\hline Table value with critical Q $\sim \chi$ with & & \\
I degree of freedom at 5\% & & \multirow{2}{|c|}{3.84} \\
significant level & & \\
\hline
\end{tabular}

\section{Discussions}

The result of this study indicated that the extent of usage for all the four dimensions of RFID (environment, organizational, technology and product) have received above moderate levels of attention in China. Judging from their values, it can be further stated that RFID is the most practiced due RFID technology is automatically shifting from people-to people communication to object-to-object communication (Chao et al., 2007). Pressed for time, a great deal of these companies does not take full advantage of the benefits of integrating RFID information back into the supply chain. RFID technology had led to much hope and optimism. The mainstream press hails RFID as the avantgarde in technology and business. For example, CNN identified RFID as one of the "Ten Technologies to Watch" in 2004, and ZDNet named RFID as one of the 10 most strategic technologies in 2005 (Wu, 2005). In Hitachi 2004 white paper, it mentioned that nothing prevents a company from coming back at a later date to leverage RFID information to improve inventory, warehousing, distribution, logistics, safety and security. While some people claim that RFID technology makes good business sense, actual RFID adoption in the real world has, thus far, been marked by failure (Adi, 2005). If a company is interested in adopting RFID technology, it must think beyond technological challenges, such as Information Technology. It must be able to see that RFID adoption is more about selling experiences than selling products or services (Adi, 2005). Information gathered from RFID has shown consumer product managers that supply chains are much less responsive than previously thought. Thus, RFID becomes a catalyst for more rapid process improvements (Jonathan, 2006).

\section{Implications, Limitations and Conclusions}

This study has shown that environment, organizational, technology and product are the four discriminating factors for RFID adoption, regardless of the moderator of supply chain. RFID is being utilized in various enterprises to improve efficiency of operation. The historical review found an increasing variety of enterprises employing RFID to improve their efficiency of operations and to gain a competitive advantage (Chao et al., 2007). As RFID technology progresses in its development and application over the next decade, there will be vast opportunities for management researchers to not only study the advancement of this technology, but to examine its implications from a wide variety of perspectives. Hence, this information can be utilized to promote the acceptance and implementation of RFID. From an organization point of view, attention should be given to improve employee participation in adopting RFID as a strategic tool.

All researches are with limitations that could be followed through by future researchers. Thus, the results have some practical implications to organizations in general. This study has not

I It is determined by computing the percentage of the total sample represented by the largest group. (Hair et al, I998)

2 Proportional Chance $=\mathrm{p} 2+(\mathrm{I}-\mathrm{p}) 2 ; \mathrm{p}$ is the proportion of individual in analysis group.

3 Press $\mathrm{Q}=[\mathrm{N}-(\mathrm{nK})] 2 / \mathrm{N}(\mathrm{K}-\mathrm{I}) ; \mathrm{N}=$ sample size; $\mathrm{n}=$ no. of samples correctly classified; $\mathrm{K}=$ no. of groups. 
included all the factors identified as relevant to the RFID context under the technology-organization-product-environment framework. Some factors, such as mimetic factors (competitive pressure, status pressure), normative factors (industry and trade associations, favorable climate) and coercive (regulatory pressure, dominating partner pressure), are not related in the framework. Thus, this can be an area for future research.

This study reveals that the environment, organization, technology and product have the impact on the adoption of RFID in China.An increasing variety of enterprises are employing RFID to strengthen their managers' ability to enhance organizational change and to manage growth in an increasingly competitive environment (Chao, Yang and Jen, 2007). An increasing number and a widening variety of enterprises are employing RFID to improve the efficiency of their operations and to gain a competitive advantage. Many industries are also launching RFID programs to help them solve their operation problems. To implement RFID, enterprises will have to resolve issues of technology development, international standards and regulations, and costs. As these issues are addressed, it is certain that RFID will continue to innovate and diffuse and that it will quickly be assimilated into our daily lives.

\section{Reference}

ACCENTURE (2004), High Performance Enabled through Radio Frequency Identification: Accenture Research on Asia Pacific Perspectives, available at: www.accenture.com/xdoc/en/ locations/korea/korea_ideas_3.pdf

ADI T. (2005). Adopting 'smart' shopping trolley no easy task. Jakarta Post on 27th June,2005.

ASIF Z. and Mandviwalla M. (2005). Integrating the Supply Chain with RFID:A technical and business analysis. Communications of the Association for Information Systems, 15, 393 - 427.

CHAO C.C., Yang J.M. and Jen W.Y. (2007). Determining technology trends and forecasts of RFID by a historical review and bibliometric analysis from 1991 to 2005. Technovation, 27, 268 279.

China Economic Times (2004). China's RFID: a business show. November 15, available at: www.cet.com.cn/2004 I I I5/FALV/ 2004I I I52.htm

FAWCETT S.E., Ogden J.A., Magnan G.M. and Cooper M.B. (2006). Organizational commitment and governance for supply chain success. The International Journal of Physical Distribution \& Logistics Management, 36, 22 - 35.

GEORGE L. (2007). Exploiting RFID digital information in enterprise collaboration. Industrial Management \& Data Systems, 107, I I $10-1122$.

GROVER V. and Goslar M.D. (1993). The initiation, adoption, and implementation of telecommunications technologies in US organizations, Journal of Management Information Systems, 10, I4I $-160$.

HUBER N., Michael K. and McCathie L. (2007). Barriers to RFID Adoption in the Supply Chain. IEEE RFID Eurasia, Istanbul, Turkey, 5-6 September 2007, I-6.

JOHATHAN G. (2006). RFID and SAP: A Strategic Vision. Computer Sciences Corporation May 2006.

LAI F.J., Joe H. and Zhang G..X. (2005). Radio frequency identification (RFID) in China: opportunities and challenges. International Journal of Retail \& Distribution Management, 33, 905 $-916$.

LINDA C. and Samuel F.W. (2007). An Inside Look at RFID Technology.Journal of Technology Management \& Innovation, 2, I 28 $-|4|$.

MARCUS J. (2005). Identification of the main factors influencing an RFID implementation in the automotive and pharmaceutical industries. http://www.ep.liu.se/exjobb/itu/2005/kts/ $015 /$

NUNNALLY, J. C., \& Bernstein, I. H. (1994). Psychometric theory (3rd Ed.). New York: McGraw-Hill.

PATTERSON K.A., Grimm C.M. and Corsi T.M. (2003).Adopting new technologies for Supply Chain Management, Research Part E: Logistics and Transportation Review, 39, 95 - I21.

SEKARAN, U. (2003), Research methods for business:A skill-building approach (4thed.), New York: John Wiley \& Son, Inc.

SCHMITT P., Thiesse F. and Fleisch E. (2006). Doption and Diffusion of RFID Technology in the Automotive Industry. Journal of the AIS, 5, $314-355$.

SHAN L.P., Gary P. and Paul R.D. (2008). Managing emerging technology and organizational transformation:An acculturative analysis. Information \& Management, 45, I53 - 163. 
SHARMA A., Citurs A. and Konsynski B. (2007). Stragetic and institutional perspectives in the adoption and early integration of Radio Frequency Identification (RFID). In: Proceedings of the 40th Hawaii International Conference on System Sciences (HICSS’07), Hawaii.

SUBRAMANI M. (2004). How do suppliers benefit from information technology use in supply chain relationships?. MIS Quarterly, 28, 45 - 73.

VIC M. (2006). The Development of a Reaearch Agenda for RFID Adoption and Effectiveness in Supply Chains. Issues in Information Systems, 3, 246 - 25I.

WU N.C., Nystrom M.A., Lin T.R. and Yu H.C. (2006). Challenges to global RFID adoption. Technovation, 26, I3 I7 - I323.

YU Q. (2007). Commercial and Industrial Applications:A Study on RFID's Adoption. TKK T-I I-.5290 Seminar on Network Security. 